\title{
Research on sound absorption properties of hydrogenated carboxyl nitrile rubber/four-hole hollow polyester fibre composites
}

\author{
DOI: 10.35530/IT.072.02.1547
}

\author{
JIE HONG
}

\section{ABSTRACT - REZUMAT \\ Research on sound absorption properties of hydrogenated carboxyl nitrile rubber/four-hole hollow polyester fibre composites}

\begin{abstract}
A series composite was prepared by adding hydrogenated carboxyl nitrile rubber (abbreviated HXNBR) as the matrix and four-hole hollow polyester (abbreviated FHHPF) as the reinforcement. The sound absorption properties of these composites were studied. The results show that with the increasing of FHHPF quantity, the storage modulus increases and the loss factor decreases gradually. On the contrary, the sound absorption performance of the composite was improved continuously. Composite with 40\% FHHPF in $1 \mathrm{~mm}$ thickness is the best. The sound absorption coefficient reached to 0.651 at $2500 \mathrm{~Hz}$ and the effective frequency range of absorption coefficient above 0.2 was $1750-2500 \mathrm{~Hz}$. When the amount of FHHPF increased to $50 \%$, negative effects of overuse shown up, that led to the decreasing of the sound absorption property. With a constant mass ratio 70/30 of HXNBR/FHHPF composite, the sound absorption performance can be enhanced by changing its thickness. However, the improvement was smaller after the thickness increased to $2 \mathrm{~mm}$. When increasing the thickness above $2 \mathrm{~mm}$, the improvement of sound absorption performance tended to move to the middle and low frequency. In the meantime, the tensile mechanical properties of the composite were significantly improved by adding FHHPF. Tensile tenacity was improved greatly and the breaking elongation is significantly decreased. The deformation of the composite was smaller and more stable, which was beneficial for the actual engineering practice.
\end{abstract}

Keywords: hydrogenated carboxyl nitrile rubber, hollow polyester, sound absorption, damping, composite

\section{Cercetări privind proprietățile de absorbție acustică a cauciucului carboxil nitril hidrogenat/compozitelor} din fibre de poliester cu miez cu patru orificii

Un compozit de serie a fost preparat prin adăugarea de cauciuc carboxil nitril hidrogenat (prescurtat HXNBR) ca matrice și poliester cu miez cu patru orificii (prescurtat FHHPF) ca armătură. Au fost studiate proprietățile de absorbție acustică a acestor compozite. Rezultatele arată că odată cu creșterea cantității de FHHPF, modulul de stocare crește și factorul de pierdere scade treptat. În plus, performanța de absorbție acustică a compozitului a fost îmbunătățită continuu. Compozitul cu 40\% FHHPF cu grosimea de $1 \mathrm{~mm}$ este cel mai performant. Coeficientul de absorbție acustică a ajuns la 0,651 la $2500 \mathrm{~Hz}$, iar gama de frecvență efectivă a coeficientului de absorbție de peste 0,2 a fost de 1750-2500 Hz. Când cantitatea de FHHPF a crescut la 50\%, au apărut efecte negative ale utilizării excesive, ceea ce a dus la scăderea proprietății de absorbție acustică. Cu un raport de masă constant 70/30 al compozitului HXNBR/FHHPF, performanța de absorbție acustică poate fi îmbunătățită prin modificarea grosimii sale. Cu toate acestea, îmbunătățirea a fost mai puțin semnificativă dacă grosimea a crescut la $2 \mathrm{~mm}$. La creșterea grosimii la peste $2 \mathrm{~mm}$, îmbunătățirea performanței de absorbție acustică a avut tendința de a se deplasa la frecvența medie și joasă. Între timp, proprietățile mecanice de tractiune ale compozitului au fost semnificativ îmbunătățite prin adăugarea de FHHPF. Rezistența la tracțiune s-a îmbunătățit foarte mult, iar alungirea la rupere a scăzut semnificativ. Deformarea compozitului a fost mai redusă și mai stabilă, ceea ce a fost benefic pentru ingineria reală practică.

Cuvinte-cheie: cauciuc carboxil nitril hidrogenat, poliester cu miez, absorbție acustică, amortizare, compozit

\section{INTRODUCTION}

Fiber material with its diverse categories and abundant sources, especially the hollow fiber was widely used in the field of sound absorption materials [1-3], but mostly in the form of nonwovens [4-6]. Rubber, as a viscoelastic polymer material, can absorb the energy and well transform to heat, especially synthetic rubber, can be used as sound-absorbing material $[7,8]$. Research of rubber as the matrix and hollow fiber blended composites for sound absorption is less. Jiang et al. used CPE as the matrix, Zhou et al. used R-Rubber as the matrix, blend with seven-hole polyester to make the CPE/SHPF and R-Rubber/ SHPF, respectively. Their studies showed that the material got the best sound absorption property when use $20 \%$ SHPF ratio with $1 \mathrm{~mm}$ thickness. Meantime, the tensile mechanical properties of the material were also well improved, and increased the material thickness can further improve its sound performance [9-11]. In addition, few such studies can be found in the published document.

According to the study of Jiang and Zhou et al., the maximum fiber content was $20 \%$ and the thickness was $3 \mathrm{~mm}$. For such materials, will continuously 
increase the fiber quantity and thickness be helpful to improve the damping and sound absorption performance? What is the changing rule? In this study, using hydrogenated carboxyl nitrile rubber (abbreviated HXNBR) as matrix and four-hole hollow polyester staple fiber (abbreviated FHHPF) as reinforcements, HXNBR/FHHPF composites in $1 \mathrm{~mm}$ thickness with different mass ratio and fixed mass ratio with different thickness were made, the influence of FHHPF content and material thickness on the sound absorption properties and its mechanism actions were studied. Furthermore, the influence on tensile properties of the material was also studied.

\section{MATERIAL FABRICATION}

The rubber matrix HXNBR used in preparation of the HXNBR/FHHPF composites marked Therban XT VP KA 8889 was manufactured by LANXESS Deutschland GMBH. The FHHPF used with fineness of 0.833 tex and length of $60 \mathrm{~mm}$ was produced by Sinopec Yizheng Chemical Fiber Co., Ltd., China. The ordinary polyester staple fiber (referred to as PF) used with fineness of 0.156 tex and length of $38 \mathrm{~mm}$ is from the same manufacturer. The cross-sectional morphology amplified 2000 of these two kind fibers were acquired by using fiber microtome and CU-2 fiber fineness tester (Beijing UVTEC Science and Technology Ltd., China) is shown in figure 1.

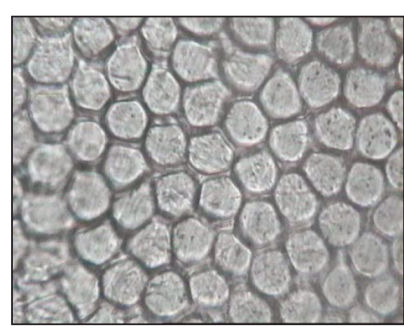

a

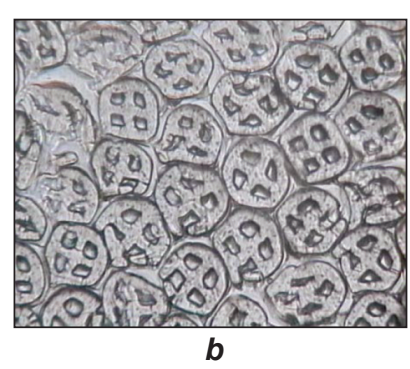

Fig. 1. Cross-sectional shape of PF and FHHPF, amplified 2000: $a-$ PF; $b-$ FHHPF
The material preparation process is as follows:

1. Mixing, when the roller temperature of the $X(S)$ K-460 double roll mill (Wuxi Chuangcheng Rubber and Plastic Machinery Co., Ltd., China) raised to $30^{\circ} \mathrm{C}$, the $\mathrm{HXNBR}$ was added into the machine for 5 min treatment, and then the weighed fibres was added in several times to make sure the materials were well mixed. The mixing time was from 20-40 min, which was depended on the fibre quantity added. A cutting knife was used to enhance the homogeneity of the composite.

2. Vulcanization, the homogenized HXNBR/polyester fibre mixture was placed in a mould, the mould was hold by a $30 \mathrm{~cm} \times 30 \mathrm{~cm}$ and $5 \mathrm{~mm}$ thickness stainless steel plate, and between the mould and steel plte, a layer of thermostable PTFE cloth with a layer of anti-sticky thermostable PET film was put on it. Then the mould was put into QLB-50D/Q type plate vulcanizing press (Wuxi Chuangcheng Rubber and Plastic Machinery Co., Ltd., China), which was preheated at 1-2 $\mathrm{MPa}$ pressure and $140^{\circ} \mathrm{C}$ for $5 \mathrm{~min}$. Then the pressure of the machine was adjusted to $10 \mathrm{MPa}$ and the material was pressed at $140^{\circ} \mathrm{C}$ for $20 \mathrm{~min}$. Release the pressure and take the mould out. Let it cool down and demould it, obtain the required material with a smooth surface.

Refer to research of Jiang, Zhou et al. and myself pre-research [10,11], six kinds of $1 \mathrm{~mm}$ thickness of HXNBR/FHHPF composite in mass ratio of $100 / 0$, 90/10, 80/20, 70/30, 60/40 and 50/50 were made respectively. Fixed mass ratio of $70 / 30$ in thickness of $0.5 \mathrm{~mm}, 2 \mathrm{~mm}, 3 \mathrm{~mm}, 4 \mathrm{~mm}$ and $5 \mathrm{~mm}$ were made respectively. HXNBR/PF material with $1 \mathrm{~mm}$ thickness was also prepared for comparison.

\section{MATERIAL TESTING}

The degree of hollowness of the used FHHPF fiber was tested. The thermodynamic performance, sound absorption properties, morphology and tensile properties of the prepared materials were tested.

Paper-cut weighing method was used for hollowness test. The cross-sectional morphology graph of the FHHPF, refer to figure $1, b$, was printed on the uniform thickness white paper, the average value was calculated from 100 fiber cross-sections randomly chosen. The test result of the hollowness of FHHPF was $22.9 \%$.

The sound absorption performance of composite was tested according to the standard of ISO 10534-2 by SW230 series impedance tube manufactured by BSWA Technology Co., Ltd., China (figure 2).

Dynamic mechanical analysis (DMA) measurements of the composites were carried out using a dynamic mechanical analyser (DMA7e, Perkin Elmer. USA) in a tension mode at a constant frequency of $1 \mathrm{~Hz}$ with a heating rate of $5^{\circ} \mathrm{C} / \mathrm{min}$. The sample size was 12 $\mathrm{mm}$ (length) $\times 4 \mathrm{~mm}$ (width) $\times 1 \mathrm{~mm}$ (thickness) .

Fractured surface morphology of the HXNBR/FHHPF composite was conducted by using a Quanta-250 environment scanning electron microscope (ESEM)

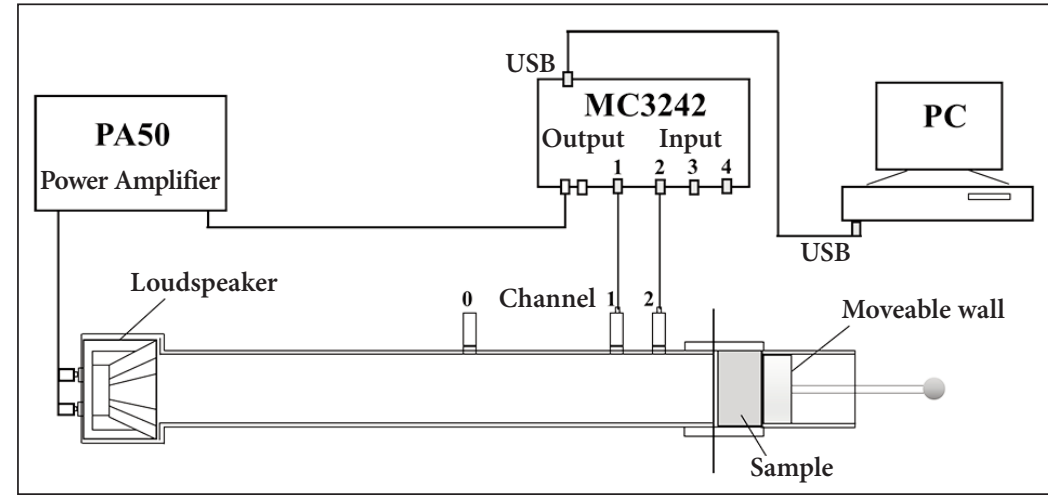

Fig. 2. Assembled diagram of measured sound absorption coefficient with an impedance tube 
(FEI Company, USA). The material samples were immersed in liquid nitrogen for a period in order to achieve brittle fracture, and then the fractured surfaces were sputter coated with gold before examination. The surface morphology of the composite was conducted by TM3000 desktop electronic scanning microscope (Hitachi, Japan). The composite surface was also sputter coated with gold before examination.

The tensile property test was conducted according to GB/T 528-2009, the test equipment was YG065 electronic fabric strength tester (Laizhou Electron Instrument Co., Ltd., Shandong, China). The tested samples were cut into dog-bone shape with $115 \mathrm{~mm}$ in length and $25 \mathrm{~mm}$ in width. The width of the narrow section was $6 \mathrm{~mm}$. The gauge length was $25 \mathrm{~mm}$. The instrument was set at a speed of $500 \mathrm{~mm} / \mathrm{min}$ for testing.

\section{RESULTS AND DISCUSSION}

$1 \mathrm{~mm}$ thickness HXNBR/FHHPF composites with different mass ratio were tested for DMA, sound absorption, SEM and tensile property. The sound absorption performance of HXNBR/FHHPF materials with mass ratio of 70/30 and different in thickness was tested. The results were analysed and studied.

\section{Influence of FHHPF content on sound absorption properties of material}

The DMA performance of different mass ratio with $1 \mathrm{~mm}$ thickness HXNBR/FHHPF composites was shown in figure 3 . From figure 3 , a, it shows that the storage modulus of HXNBR/FHHPF increased with the increasing of the FHHPF fibre content, and the transition temperature moved toward to a higher temperature. Meanwhile, in figure 3, $b$, at the initial only $10 \%$ FHHPF was added, the loss factor decreased in a large amplitude, but the glass transition temperature ( $\mathrm{Tg}$ ) had a significant movement toward to the higher temperature direction. With the increasing of the FHHPF content, the loss factor of the material continued to decrease and the Tg moved toward to

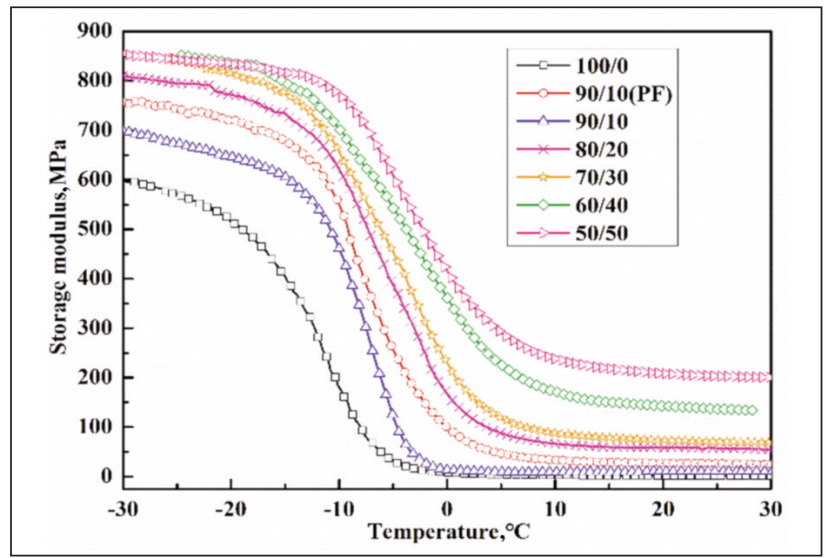

a the higher temperature direction, but the changing was relatively small.

Adding FHHPF in the material to change the damping properties of HXNBR/FHHPF was due to the high modulus of the fibre itself and the storage modulus of the material can be increased based on its reinforcing effect. At the same time, the interaction between the fibre and the matrix restrains the movement of the HXNBR molecular chain, which promoted the decreasing of the loss factor [12, 13]. With the increasing of the FHHPF content, the interfacial interaction between fibre and matrix was strengthened, and the motion of HXNBR molecular chain segment was restricted more. In the meanwhile, the decreasing of HXNBR content led to the decreasing of the total molecular segment motion. Furthermore, undergone the mixing and vulcanization process, from the cross-section SEM of the material in figure 4, $a$, it can be found that the gradually increased fibres were evenly dispersed in the matrix to form a fibre web, which were entangled with each other and further restricted the movement of the HXNBR molecular chain segment [11-13]. The material storage modulus was improved, but at the same time, the material loss factor decreased and the $\mathrm{Tg}$ moved toward to the higher temperature.

The sound absorption performance of HXNBR/FHHPF with different mass ratio of $1 \mathrm{~mm}$ thickness is shown in figure 5. It can be found that pure HXNBR has a certain sound absorption capacity, and the sound absorption coefficient is 0.245 at $2500 \mathrm{~Hz}$. Generally, material with sound absorption coefficient greater than 0.2 can be called sound-absorption material [14], so the frequency range with the sound absorption coefficient not less than 0.2 can be used to determine the material's sound absorption capacity. For pure HXNBR, the frequency range with sound absorption coefficient greater than 0.2 is merely $2300-2500 \mathrm{~Hz}$. With reference to the damping property of the pure HXNBR in figure 3, sound absorption capacity is resulted from its excellent viscoelastic internal damping characteristics. From figure 5, it can be found that the sound absorption has been improved to a certain extent by adding PF.

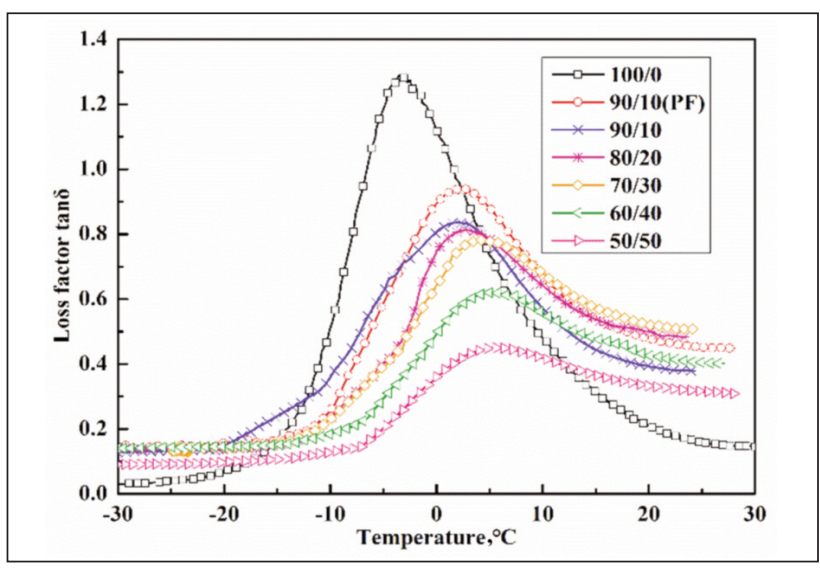

b

Fig. 3. Damping property of HXNBR/FHHPF composites: a - storage modulus-temperature curve; $b$ - loss factor-temperature curve 


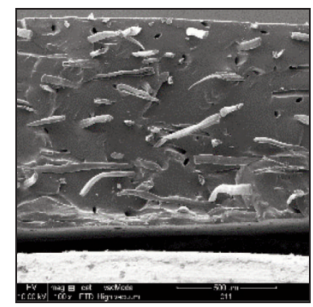

a

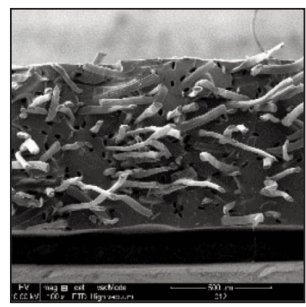

b

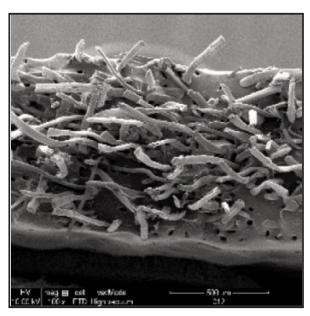

c

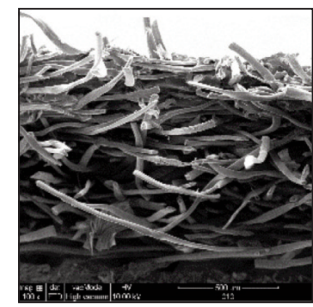

$d$

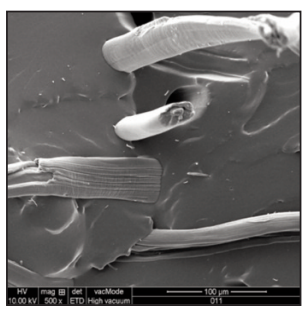

e

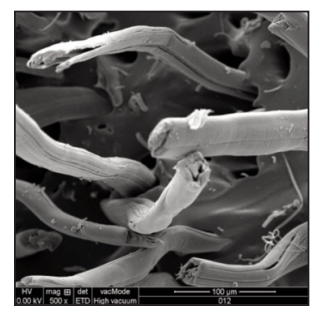

$f$

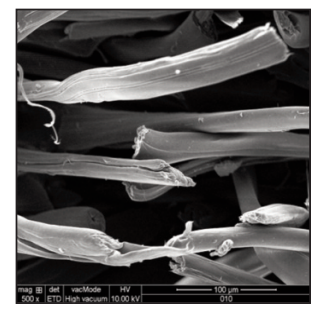

g

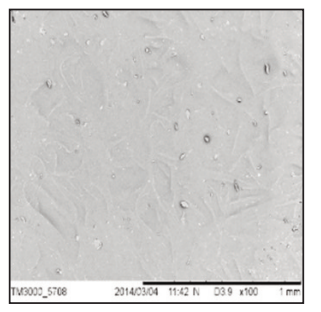

h

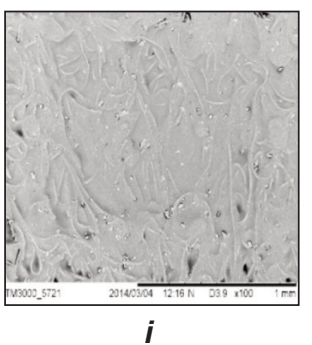

Fig. 4. SEM of HXNBR/FHHPF materials: $a$ - cross section 90/10, amplified $100 ; b$ - cross section $80 / 20$, amplified 100; $c$-cross section 70/30, amplified 100; $d$-cross section 50/50, amplified 100; e - cross section 90/10, amplified $500 ; f$ - cross section 70/30, amplified 500; $g$ - cross section 50/50, amplified 500; $h$ - surface 70/30, amplified 100; $i$ - surface 50/50, amplified 100

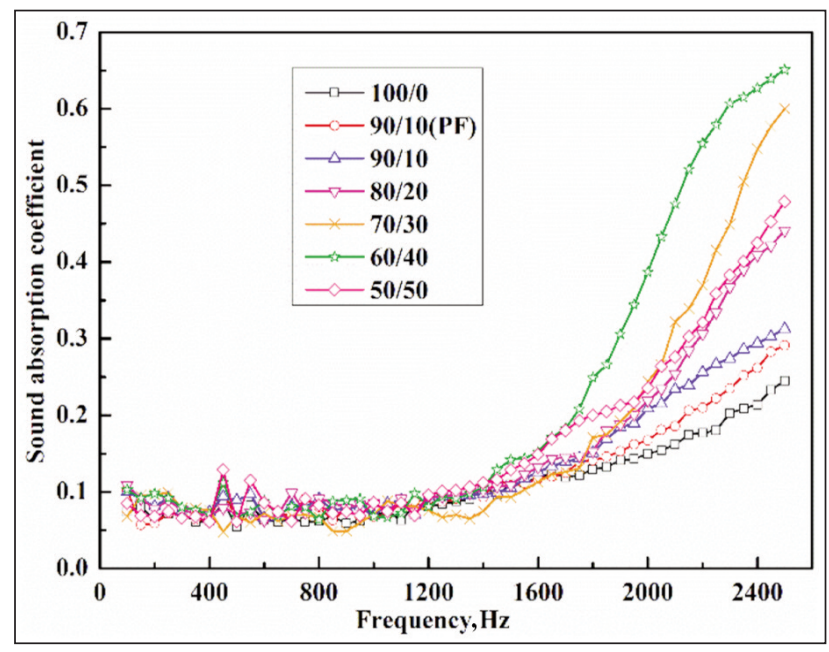

Fig. 5. Sound absorption property of HXNBR/FHHPF composites

The sound absorption coefficient of HXNBR/PF is 0.291 at $2500 \mathrm{~Hz}$ and the frequency range of sound absorption coefficient greater than 0.2 is slightly widened to $2150-2500 \mathrm{~Hz}$. Combined with figure 3, the material storage modulus increases by adding of $10 \%$ PF, but with a substantial declining of the loss factor, so the energy consumption sound absorption capacity that based on the damping characteristic of the material decreased. However, overall sound absorption performance has improved, which can be concluded that other sound absorption energy dissipation mechanism played a role. It is believed that this is mainly based on the adding of fine short PF, which is evenly distributed in the matrix and interacts with the matrix. The sound absorption of HXNBR/PF is extended from the original single HXNBR viscoelastic damping energy dissipation to the viscoelastic damping energy consumption, fibre viscosity and heat conduction, the friction between fibre itself vibration and matrix generated under the combined effect of energy consumption [9, 10].

Therefore, the use of PF to improve the sound absorption capacity of HXNBR/PF makes up for the reduction of the rubber matrix that resulted in the decreasing of the viscoelastic damping energy consumption of sound-absorbing performance, the general performance has been improved. However, as far as the frequency range of sound absorption coefficient greater than 0.2 and the corresponding sound absorption coefficient at every frequency point, the use of PF in the material has limited effect in improving the sound absorption performance.

Therefore, use 10\% FHHPF to instead PF, the corresponding figure 5 shows that the sound absorption has been further improved, the sound absorption coefficient reached to 0.313 at $2500 \mathrm{~Hz}$, and the frequency range of sound absorption coefficient greater than 0.2 is $2000-2500 \mathrm{~Hz}$. When consider figure 3, the storage modulus and loss factor of PF is higher than FHHPF. Therefore, based on the sound absorption mechanism of used PF, there are other sound absorption energy dissipation mechanism effects that further improved the sound absorption performance of used FHHPF. From figure 1 of the fibre cross-section we can see the FHHPF is four-hole hollow, the hollowness testing result is $22.9 \%$. With this characteristic, there are many pores and static air in the HXNBR/FHHPF. Meanwhile, as FHHPF is evenly distributed in the matrix and the cutting effect prompts more gaps in the matrix. When the sound wave enters the material, the air vibrates in the pore, the viscosity of the air and the friction between the air and cavity wall cause the increasing of energy consumption. Therefore, the sound absorption performance of the composite material has been greatly improved $[9,10,15]$. 


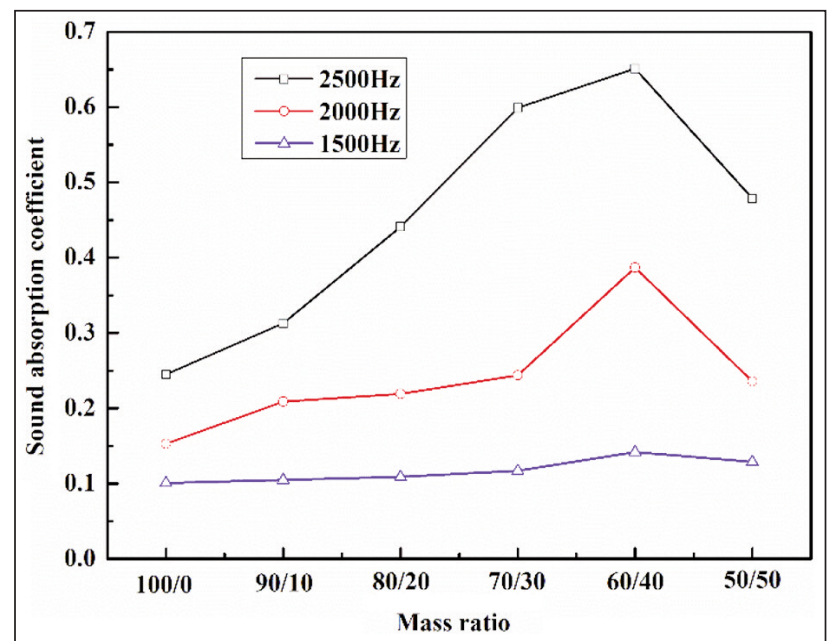

Fig. 6. Sound absorption coefficient of HXNBR/FHHPF material in main frequency point

Continue to increase the FHHPF content, from figure 5, it can be found that when the FHHPF content is less than $40 \%$, the sound absorption performance of the HXNBR/FHHPF material was improved with the increasing of the FHHPF quantity. It is shown consistent sound absorption characteristics with porous material, the sound absorption property was improved with the increasing of frequency [16], and effect that is more significant was found especially when the frequency is above the $1600 \mathrm{~Hz}$. The change trend of sound absorption coefficient in the main frequency point was shown in figure 6 . At the same time, the frequency range of the sound absorption coefficient greater than 0.2 was also gradually broadened, which broadened from the high frequency of $2000 \mathrm{~Hz}$ above to medium frequency of $2000 \mathrm{~Hz}$ below. When the FHHPF reached to $40 \%$, the sound absorption coefficient at $2500 \mathrm{~Hz}$ was up to 0.651 , the frequency of sound absorption coefficient greater than 0.2 frequency range from $1750 \mathrm{~Hz}$ to $2500 \mathrm{~Hz}$. This change of the sound absorption performance is due to the increasing of porosity because of the increasing of the FHHPF content, the air layer gradually penetrate, the interaction between the fibre and the matrix, and the gradual formation of the fibre web so the interaction between fibres also strengthens the ability to consumption sound energy $[9,10]$. with different FHHPF contents was calculated according to the equation:

$$
K=1-\rho \times \sum_{i=1}^{n} \frac{c_{i}}{\rho_{i}}
$$

where $K$ is porosity of composite, $\rho-$ the material density, $c_{i}$ - the volume density of each composite, $\rho_{i}$ - the volume density of each material $[15,17]$. The volume density of the HXNBR/FHHPF is in table 1 . The volume density of FHHPF was tested by density gradient method. After getting the volume density of the material, the calculated porosity of the materials are shown in table 2.

From table 2, it can be seen that when the mass ratio of HXNBR/FHHPF is $90 / 10$, the porosity of the material is $6.375 \%$, and the cross-sectional SEM of the material in figure 4 shows that the fiber is less and evenly distributed and solidified in the matrix, the pores does not exert its best energy-absorbing sound absorption. When the fiber content increased to $20 \%$, the porosity of the material is $10.688 \%$, in contrast to the cross-sectional SEM observation from figure 4, it can be seen that more fibers come into contact with each other, but a perfect fiber web has not yet been formed. In this composite, part of the air layers in the pores are interpenetrated with each other, meanwhile there has vibration friction between fibers, coupled with the enhancement of the friction between the fiber and the matrix, the sound absorption performance has been greatly improved. The sound absorption coefficient at $2500 \mathrm{~Hz}$ increased to 0.441 . Refer to table 2, further increasing the FHHPF quantity to $30 \%$, the porosity increases to $14.514 \%$. From figure 4 , it can be found that a relatively complete fiber network is formed, so that the existence of air in the pores interpenetrated with each other and showed a good energy consumption sound absorption property. Vibration friction between fiber-fiber and fiber-matrix is also much stronger, so the energy consumption of the material raised and the sound absorption property is improved. The sound absorption coefficient at $2500 \mathrm{~Hz}$ reaches to 0.599 . When the quantity of FHHPF is $40 \%$, the porosity attains the maximum of $16.089 \%$, the web between fibers is more perfect, and more air exists and penetrates each other. The vibration friction between fiber-fiber and fiber-matrix promoted more energy consumption

Table 1

\begin{tabular}{|l|c|c|c|c|c|c|c|}
\hline \multicolumn{1}{|c|}{ VOLUME DENSITY OF HXNBR/FHHPF MATERIAL } \\
\hline Ratio & $100 / 0$ & $90 / 10$ & $80 / 20$ & $70 / 30$ & $60 / 40$ & $50 / 50$ & $0 / 100$ \\
\hline Density $\left(\mathbf{g} / \mathbf{c m}^{\mathbf{3}}\right)$ & 0.97 & 0.929 & 0.907 & 0.889 & 0.894 & 0.938 & 1.25 \\
\hline
\end{tabular}

For porous sound absorption material, the porosity has an important influence on the sound absorption performance. Based on the use of FHHPF, the existence of voids in HXNBR/FHHPF composites and air content will have an influence on the sound absorption performance. The porosity of HXNBR/FHHPF 
sound absorption. The composite has achieved the best sound absorption property.

According to figure 5 and figure 6 , the sound absorption performance increases with the increasing of FHHPF content especially obvious at higher frequency area. That is because the higher frequency sound wave can more easily cause vibration after it gets into the material and the energy consumption of the material increased under various sound absorption effect. The fiber web formed by FHHPF in the HXNBR/FHHPF can be regarded as a kind of microstructure of the porous material which is good at absorbing higher frequency sound wave. The more FHHPF in the material, the better sound absorption capability at high frequency area will be [5]. However, further increasing the ratio of FHHPF to $50 \%$, the sound absorption performance of the material decreased in a large extent. The sound absorption coefficient at $2500 \mathrm{~Hz}$ is 0.479 and the frequency range of sound absorption coefficient larger than 0.2 is also slightly narrowed to $1800-2500 \mathrm{~Hz}$. From table 2, it can be found that the porosity of the material decreased to $14.126 \%$, which indicates that the negative effects begin to appear when FHHPF content reached to a certain value. The cross-section and surface SEM of HXNBR/FHHPF composite with $50 \%$ FHHPF content in figure 4 shows that the fiber web is too dense and the FHHPF entangled with each other, and the material was compressed under plate compression, so the porosity of the material decreased. The vibration friction between fibers and the elastic deformation of HXNBR has been greatly limited, so the internal damping viscoelastic loss effect of the material decreased. The loss factor-temperature curve of HXNBR/FHHPF composite withe FHHPF content $50 \%$ in figure 3 is also confirmed above analysis. Besides, the entanglement of the excess fiber depressed the friction-energy consumption between FHHPF and HXNBR. Therefore, the sound absorption property of the material turned worse.

\section{Influence of material thickness on sound absorption property}

From the above analysis of the sound absorption properties of HXNBR/FHHPF composites with different ratio of FHHPF, we can see that the improvement of the sound absorption performance is mainly in the high-frequency region above $1600 \mathrm{~Hz}$, almost no improvement in the low frequency sound absorption performance. According to the research report, the sound absorption performance of the material can also be improved by increasing the thickness of the material $[10,11,18]$. For this purpose, the HXNBR/ FHHPF composites with mass ratio of $70 / 30$ was made into different thickness for study, the thickness of these materials are $0.5 \mathrm{~mm}, 1 \mathrm{~mm}, 2 \mathrm{~mm}, 3 \mathrm{~mm}$, $4 \mathrm{~mm}$ and $5 \mathrm{~mm}$ respectively. The sound absorption property of these composites can be seen in figure 7 . HXNBR/FHHPF material with thickness in $0.5 \mathrm{~mm}$ already has good sound absorption performance.
The sound absorption coefficient at $2500 \mathrm{~Hz}$ is 0.329 , the frequency range of sound absorption coefficient larger than 0.2 is $2000-2500 \mathrm{~Hz}$. When the thickness of the material increased to $1 \mathrm{~mm}$ and $2 \mathrm{~mm}$, the sound absorption performance improved significantly at $2000 \mathrm{~Hz}$ and above. The sound absorption coefficient at $2500 \mathrm{~Hz}$ increased to 0.599 and 0.795 respectively. The frequency range of sound absorption coefficient larger than 0.2 of the two materials is widened to $1900-2500 \mathrm{~Hz}$ and $1850-2500 \mathrm{~Hz}$ respectively. However, for the middle and low frequency that below $2000 \mathrm{~Hz}$, there is almost no improvement. This is because low frequency sound wave induces small vibration that cannot effectively cause the energy consumption of the rubber matrix and FHHPF, which are consistent with the sound absorption mechanism of the porous sound-absorbing material [19]. When increasing the thickness from $2 \mathrm{~mm}$ to $3 \mathrm{~mm}, 4 \mathrm{~mm}, 5 \mathrm{~mm}$, it is hard to improve the sound absorption coefficient of the high-frequency region, the sound absorption coefficient at $2500 \mathrm{~Hz}$ is $0.802,0.806$ and 0.811 respectively. However, the improvement in the middle and low frequency direction is gradually significant, especially in 1200-2000 $\mathrm{Hz}$ range. From figure 7 , we can find that the frequency ranges of sound absorption coefficient larger than 0.2 of the three kinds of thickness material are widened to $1800-2500 \mathrm{~Hz}, 1700-2500 \mathrm{~Hz}$, and 1450-2500 Hz, respectively.

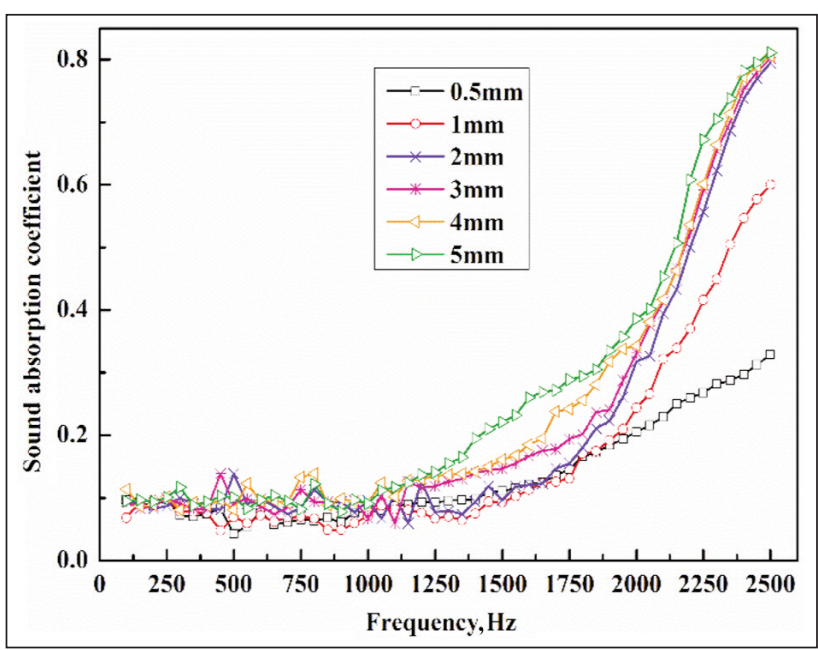

Fig. 7. Effect of thickness of HXNBR/FHHPF composites with $30 \%$ FHHPF on sound absorption property

This shows that the increasing of the composite thickness can effectively improve the sound absorption properties of the material, but when the thickness increased to a certain value, the improvement is small. In considering the economic applicability, appropriate thickness of the material should be chosen. Improving the sound absorption performance of the material by increasing its thickness is mainly because of the increasing of the propagation distance. The sound waves through HXNBR viscoelastic damping energy dissipation, the vibration energy dissipation between FHHPF, the air viscous effect of the sound wave caused by the presence of pores of 
the FHHPF, and the relative increased energy dissipation caused by the friction between the air and the cavity wall. All the above lead to more energy being absorbed by the material and the sound absorption property of the material is improved [20]. Continue to increase the thickness above $2 \mathrm{~mm}$, the sound absorption improvement tends to move to the low and medium frequency direction which is consistent with other document $[16,18,21]$. This is because of the better penetrating power of the lower frequency sound wave. When increasing the material to certain thickness, all kinds of sound absorption mechanism in the material can be fully exerted that more low frequency sound energy is attenuated, so the sound absorption performance in the middle-low region is largely improved. In the high-frequency region, due to the increasing of the material thickness, the acoustic impedance increases accordingly. In this situation, the reflective ability of the material to the sound waves is enhanced, and the high-frequency acoustic waves which get into the material are reduced. Therefore, when the thickness increases to a certain level, sound absorption performance of high-frequency is no longer significant, the increasing of the sound absorption coefficient is relatively small [19].

\section{The tensile mechanical property of the material}

From the above analysis, it can be concluded that the use of FHHPF can significantly improve the sound absorption performance of the $1 \mathrm{~mm}$ thickness HXNBR/FHHPF composites for frequency over 1600 $\mathrm{Hz}$, and whether the material has excellent mechanical properties is important for practical application in the engineering field. Tensile mechanical properties of HXNBR/FHHPF composites with different mass ratios are shown in figure 8 . The influence of FHHPF content on the tensile properties of the material is shown in figure 9.

It can be seen from figure 8 that the strain of pure HXNBR matrix is very large, and it can produce great deformation under very small stress. The tensile breaking tenacity of the pure HXNBR matrix is only 6.3 $\mathrm{MPa}$, and the elongation at break is as high as

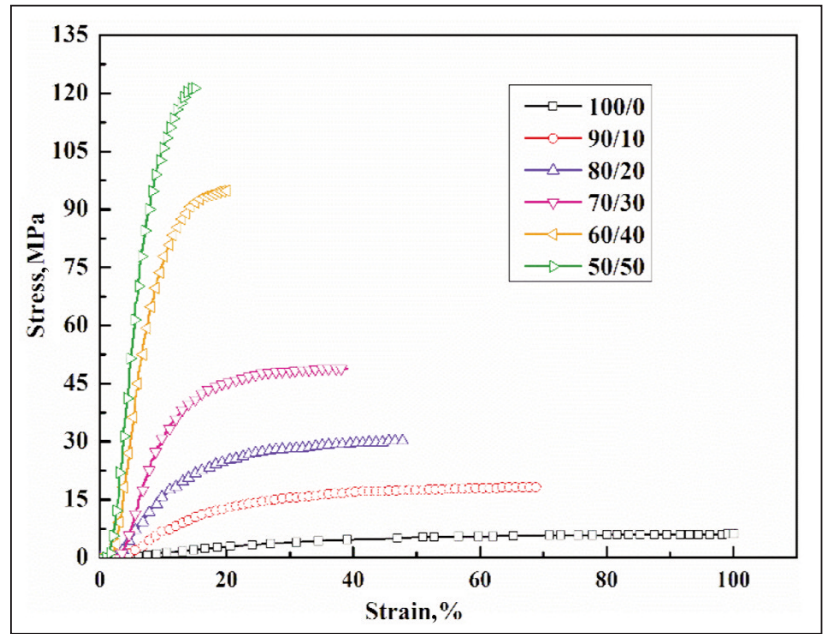

Fig. 8. Tensile stress-strain curves of the composites
$100.5 \%$. The mechanical properties are improved significantly after adding FHHPF. With the increasing of the fiber content gradually up to $50 \%$, the strain of the material gradually decreases, especially when the fiber content over $30 \%$, the tensile strain of the material is greatly decreased and its strength is greatly improved. Figure 9 clearly shows the influence of the FHHPF ratio on the mechanical properties of the materials.

Pure HXNBR material is subjected to external force alone when the material is being stretched. The stress-strain characteristic of the rubber is shown in figure 8. When add a small amount of FHHPF, the FHHPF is homogeneously dispersed in the HXNBR matrix after mixing and vulcanizing. From the SEM of the material in figure 4, a we can find that the fibers are not continuous. When the material is subjected to external tensile force, the external force is transmitted to the fiber through the fiber matrix interface and the interfacial bonding between the FHHPF and the HXNBR matrix enables the fiber and the substrate to bear the external stress effectively and limit the deformation of the rubber matrix simultaneously [22]. In addition, compared with the pure HXNBR, when the HXNBR/FHHPF composite is under external force, besides the fracture of the original HXNBR matrix, the pull out friction between the fiber and the matrix during the pulling process and some fibers ruptured, under the combine action, the tensile strength of the material is improved. However, the HXNBR matrix still plays the main role in strength property of material in this situation, so although the elongation at break is lower, but the material deformation is still large [22-24]. With the further increasing of FHHPF content, the fibers were evenly distributed in the matrix and a dense fiber web was formed gradually. From the SEM in figure 4 , it can be found that the FHHPF is in bending and twisting state in HXNBR matrix. The three-dimensional fiber crimp also helps to strengthen the interface binding force between the fiber and matrix which improved the ability of bearing external force. The breaking strength of the material is further improved when the content of FHHPF is

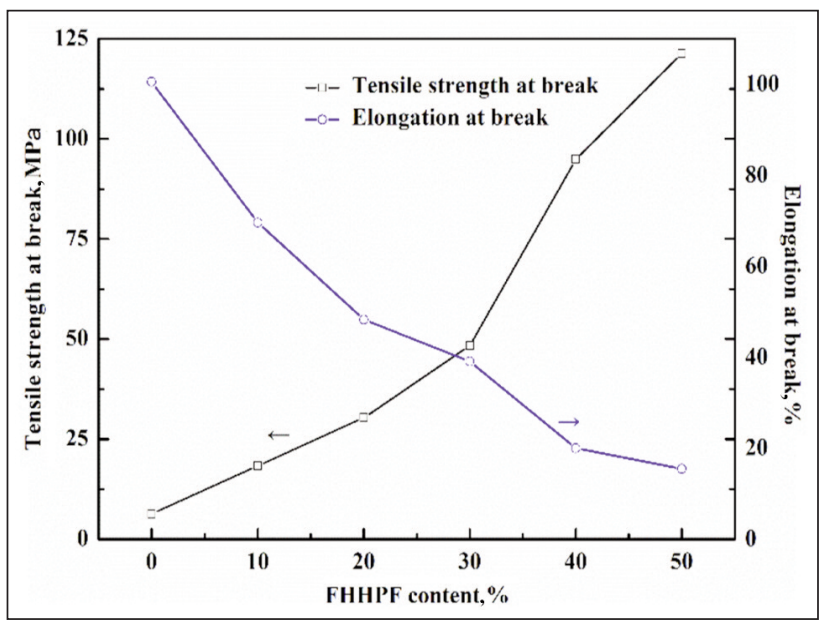

Fig. 9. Effect of FHHPF content on tensile mechanical properties of composites 
increased to $30 \%$ and above. Meanwhile, the increasing of FHHPF fiber can restrain the elastic deformation of HXNBR and the material is more stable. The main role bear external force is gradually transferred to FHHPF fiber, more fibers ruptured when under external force, the pull-off of the fibers make a lot of tiny cracks and holes in the material that will lead to earlier breakage of the HXNBR.

The material elongation at breakage is gradually decreased especially significant when the content reaches to $30 \%$ and above [25].

\section{CONCLUSIONS}

A series of HXNBR/FHHPF composites were prepared. After the study of the sound absorption properties and the tensile properties of these materials, the following conclusions are drawn.

- The storage modulus of HXNBR/FHHPF increased with the increasing of FHHPF, but the loss factor gradually decreased and the corresponding $\mathrm{Tg}$ moved to the higher temperature region, which is based on the use of FHHPF to make its energy storage increased. In addition, the interaction of the fiber-matrix and the gradually formed fiber web limit the motion of HXNBR molecular chain segment. This effect is enhanced by the increasing use of FHHPF, so the peak value of the material loss factor decreases, the corresponding $\mathrm{Tg}$ moves to the higher temperature direction.

- The sound absorption performance of HXNBR/ FHHPF composite is characterized as porous sound-absorbing material. The higher the frequency is, the higher the sound absorption coefficient is, and both increases with the increasing of FHHPF content. It gains the best sound absorption property at $40 \%$ FHHPF. The coefficient peak value is 0.651 , and the effective frequency domain with sound absorption coefficient greater than 0.2 is 1750-2500 Hz. The excellent sound absorption performance of the material is due to the use of
FHHPF. With the increasing of the FHHPF content in the material, the porosity of the material increases, the air layer penetrates gradually, the friction between the fiber and the matrix increases, and the friction between the fibers increases after forming as a web. That enhances the consuming of the sound energy. Continue to increase the FHHPF content to $50 \%$, due to the excessive entanglement between fiber web, it suppresses the vibration of the friction between the fibers and the elastic deformation of the HXNBR. Meanwhile, through vulcanizing press process, the porosity of the material also decreased. In combined aspects, the sound absorption performance decreased after the FHHPF reaching to $50 \%$.

- Keep the $30 \%$ ratio of FHHPF, and gradually increase the thickness of the HXNBR/FHHPF composite from $0.5 \mathrm{~mm}$ to $5 \mathrm{~mm}$, the sound absorption coefficient of the material increases while the effective frequency domain of the sound absorption coefficient greater than 0.2 also be widened. However, when continue increasing the thickness from $2 \mathrm{~mm}$ to $3 \mathrm{~mm}$ and above, there is limit improvement in the sound absorption performance in high-frequency region while relatively significant improvement in low-frequency.

- Adding the FHHPF to HXNBR is not only improving the sound absorption of the material over the frequency range of $1600 \mathrm{~Hz}$, but also improves the tensile properties. With the increase of FHHPF content, the tensile strength of the material gradually increases and the strain gradually decreases. This contributes to the practical application of materials in engineering.

\section{ACKNOWLEDGEMENTS}

We would like to thank the financial support of Top-notch Academic Programs Project of Jiangsu Higher Education Institutions (No. PPZY2015A093), Qing Lan Project in Jiangsu Province (2020).

\section{REFERENCES}

[1] Xiang, H.F., Zhao, N., Xu, J., Recent progress in sound absorption materials based on polymer fibers, In: Polymer Bulletin, 2011, 5, 1-9

[2] Xiang, H.F., Wang, D., Liu, H.C., et al., Investigation on sound absorption properties of kapok fibers, In: Chinese Journal of Polymer Science, 2013, 31, 3, 521-529

[3] Liu, X.T., Yan, X., Li, L., et al., Sound-absorption properties of kapok fiber nonwoven fabrics at low frequency, In: Journal of Natural Fibers, 2015, 12, 4, 311-322

[4] Gliscinska, E., Michalak, M., Krucinska, I., Sound absorption property of nonwoven based composites, In: AUTEX Research Journal, 2013, 13, 4, 150-155

[5] Hassanzadeh, S., Hasani, H., Zarrebini, M., Analysis and prediction of the noise reduction coefficient of lightlyneedled Estabragh/polypropylene nonwovens using simplex lattice design, In: Journal of the Textile Institute, 2014, $105,3,256-263$

[6] Santhanam, S., Bharani, M., Temesgen, S., et al., Recycling of cotton and polyester fibers to produce nonwoven fabric for functional sound absorption material, In: Journal of Natural Fibers, 2018, 1, 1-7

[7] Zhou, H., Huang, G.S., Chen, X.R., et al., Advances in sound absorption polymers, In: Rubber \& Plastics Resources Utilization, 2004, 16, 3, 450-455

[8] Chen, R.J., Rubber sound absorption material and their application, In: China Rubber Industry, 2008, 55, 2, 122-125

[9] Jiang, S., Yan, X., Acoustical absorption property of elastomer composites consisting of chlorinated polyethylene and seven-hole hollow polyester fibers, In: Journal of Textile Research, 2010, 31, 3, 32-35 
[10] Jiang, S., Xu, Y.Y., Zhang, H.P., et al., Seven-hole hollow polyester fibers as reinforcement in sound absorption chlorinated polyethylene composites, In: Applied Acoustics, 2012, 73, 3, 243-247

[11] Zhou, X.O., Jiang, S., Yan, X., et al., Damping acoustic properties of reclaimed rubber/seven-hole hollow polyester fibers composite materials, In: Journal of Composite Materials, 2014, 48, 26, 3249-3254

[12] Jin, Z., Wu, X.Y., Luo, Z., et al., Complex modification of polyamide fiber and the research of polyamide fiber reinforced natural rubber composites, In: New Chemical Materials, 2015, 43, 4, 149-151

[13] Xia, Z.L., Luo, Z., Lou, J.F., et al., Study on the properties of aramid fiber reinforced natural rubber, In: Special Purpose Rubber Products, 2013, 34, 6, 15-20

[14] Su, W., Li, X.Y., Liu, S.S., Influence of thickness and density on sound-absorption capability of nonwoven soundabsorbing material, In: Journal of Tianjin Polytechnic University, 2009, 28, 3, 34-36

[15] Jiang, S., Structure and properties of hollow fiber as reinforcement in acoustics absorption wasted rubber composites, In: Polymer Materials Science and Engineering, 2015, 31, 12, 73-77

[16] Lou, C.W., Lin, J.H., Su, K.H., Recycling polyester and polypropylene nonwoven selvages to produce functional sound absorption composites, In: Textile Research Journal, 2005, 75, 5, 390-394

[17] Yilmaz, N.D, Banks-Lee, P., Powell, N.B., et al., Effects of porosity, fiber size, and layering sequence on sound absorption performance of needle-punched nonwovens, In: Journal of Applied Polymer Science, 2011, 1215, 3056-3069

[18] Lee, Y.E., Joo, C.W., Sound absorption properties of thermally bonded nonwovens based on composing fibers and production parameters, In: Journal of Applied Polymer Science, 2004, 92, 4, 2295-3302

[19] Shen, Y., Jiang, G.M., Ji, T., et al., Analysis of sound absorbing properties of activated carbon fiber materials, In: Journal of Textile Research, 2013, 34, 3, 1-4

[20] Seddeq, H.S., Aly, N.M., Ali, M.A., et al., Investigation on sound absorption properties for recycled fibrous materials, In: Journal of Industrial Textiles, 2013, 43, 1, 56-73

[21] Wang, C.N., Torng, J.H., Experimental study of the absorption characteristics of some porous fibrous materials, In: Applied Acoustics, 2001, 62, 4, 447-459

[22] Manaila, E., Stelescu, M.D., Doroftei, F., Polymeric composites based on natural rubber and hemp fibers, In: Iranian Polymer Journal, 2015, 24, 2, 135-148

[23] Leny, M., Narayanankutty, S., Cure characteristics and mechanical properties of HRH bonded nylon-6 short fibernanosilica-acrylonitrile butadiene rubber hybrid composite, In: Polymer-Plastics Technology and Engineering, 2008, 48, 1, 75-81

[24] Zainudin, E.S., Yan, L.H., Haniffah, W.H., et al., Effect of coir fiber loading on mechanical and morphological properties of oil palm fibers reinforced polypropylene composites, In: Polymer Composites, 2014, 35, 7, 1418-1425

[25] Han, Z., Qi, S., Wei, L., et al., Surface-modified polyimide fiber-filled ethylenepropylenediene monomer insulations for a solid rocket motor: processing, morphology, and properties, In: Industrial \& Engineering Chemistry Research, $2013,52,3,1284-1290$

\author{
Authors: \\ JIE HONG ${ }^{1,2}$ \\ 1 Jiangsu College of Engineering and Technology, Nantong, Jiangsu, China \\ 2Jiangsu Advanced Textile Engineering Technology Center, Nantong, Jiangsu, China \\ Corresponding author: \\ JIE HONG \\ e-mail: 85391392@qq.com
}

